\title{
On the Observations of Seismic-Electric Effect and the Induced Polarization Potential on Minusinsk Gas Deposit Field in the Natural Noise Fields of the Earth
}

\author{
Georgy Ya. Shaidurov, \\ Danil S. Kudinov* and Vadim S. Potylitsyn \\ Siberian Federal University \\ 79 Svobodny, Krasnoyarsk, 660041, Russia
}

Received 22.09.2016, received in revised form 31.10.2016, accepted 29.11.2016

The paper describe the exploration of seismic-electric phenomenon and the effect of the induced polarization by passive method, which is extracting information from natural the electrical and seismic noise of the Earth in the frequency range of 1-20 Hz. This research was performed in the period 29-31 August 2014 at the Novo-Mikhailovskaya area of Minusinsk condensate field (Rep. Khakassia). We have used the device developed at the Siberian Federal University VPEMPZ-M1 (Noise-6). Productive reservoir was detected by the cross-correlation coefficient of seismic and electrical noise. The potential gradient induced polarization was in 5-7 times higher than normal background. In 2015, the experiment was repeated in two areas of the same field, Bistriynskiy and Novo-Mikhailovskiy area, which confirmed the results of 2014.

Keywords: seismic noise, electrical noise, induced polarization, cross-correlation function, gas and condensate field, the cross-correlation.

Citation: Shaidurov G.Ya., Kudinov D.S., Potylitsyn V.S. On the observations of seismic-electric effect and the induced polarization potential on minusinsk gas deposit field in the natural noise fields of the earth, J. Sib. Fed. Univ. Eng. technol., 2016, 9(8), 1353-1365. DOI: 10.17516/1999-494X-2016-9-8-1353-1365.

(c) Siberian Federal University. All rights reserved

* Corresponding author E-mail address: kudinovdanil@yandex.ru 


\title{
О наблюдении сейсмоэлектрического эффекта
}

\author{
и потенциалов вызванной поляризации \\ на Минусинском газоконденсатном месторождении \\ в естественных шумовых полях Земли
}

\author{
Г.Я. Шайдуров, \\ Д.С. Кудинов, В.С. Потылицын \\ Сибирский федеральный университет \\ Россия, 660041, Красноярск, пр. Свободный, 79
}

\begin{abstract}
В статье описано исследование сейсмоэлектрических (СЭ) явлений и эффекта вызванной поляризации (ВП) по пассивному методу, позволяющему извлекать информацию из естественных электрических и сейсмических иумов Земли в диапазоне 1-20 Ги. Это исследование было проведено в период 29-31 августа 2014 г. в районе Ново-Михайловской площади Минусинского газоконденсатного месторождения (Республика Хакасия). Использовался прибор ВПЕМПЗ-М1 (Шум-6), разработанный в Сибирском федеральном университете. Продуктивная залежь была отмечена повышением значения коэффициента взаимной корреляции сейсмических и электрических помех, а также градиентом потенциала вызванной поляризачии, получаемым из сигналов, снимаемых с двух смежных электрических диполей. В 2015 г. эксперимент по СЭ был повторен на двух площадях этого же месторождения, Быстрянской и Ново-Михайловской площади. Эксперимент, подтвердивщий результаты 2014 г.
\end{abstract}

Ключевые слова: сейсмические шумы, электрические шумы, вызванная поляризация, взаимнокорреляционная функция, газоконденсатное месторождение.

\section{Введение}

Основной проблемой поиска и разведки углеводородов в Восточной Сибири является чрезвычайная неоднородность верхней части разреза, осложненной трапповыми включениями магматических пород, маломощностью продуктивных залежей (10 м) с экранированием солевыми отложениями. В этих условиях традиционные методы сейсморазведки не дают однозначных результатов, велика вероятность пропуска. Из 10 дорогостоящих скважин лишь 1-2 подтверждаются выходом полезного продукта.

Использование комплекса геофизических методов, безусловно, улучшает качество распознавания залежей нефти и газа. По этой причине привлечение новых физических параметров, удешевление постановки работ сегодня чрезвычайно актуальны.

Новое направление идентификации продуктивных залежей - технология АНЧАР [1, 2], основанная на регистрации сейсмических сигналов в течение достаточно большого времени (1 млн и более) после воздействия на разрез взрывом или ударом невзрывных источников. В [3] описана пассивная технология сейсморазведки, основанная на регистрации микросейсм. Классическим способом геокартирования по кажущемуся сопротивлению служит магнитнотеллурический метод, заключающийся в наблюдении магнитных либо электрических компонент теллурических токов в диапазоне инфранизких частот $(0,01 \div 1$ Гц) [4].

Еще одним электроразведочным способом, применяемым в разведке углеводородов, выступает метод вызванной поляризации (ВП), реализуемый путем регистрации переходных ха- 
рактеристик электрических потенциалов при пропускании через разрез поляризующего тока от специальных источников $[5,6]$. Метод традиционно используется при поиске полиметаллических руд. При этом появление потенциалов ВП объясняется разрядом двойного электрического слоя на границах раздела электронной (руда) и ионной (окружающая горная порода, насыщенная водой) проводимостей.

Потенциалы ВП на границах залежей углеводородов, по-видимому, имеют другое происхождение, поскольку речь идет о границе раздела пористой породы, насыщенной диэлектриком (углеводороды), в ионопроводящей среде. В этом случае на окружающую среду движется разряд электрической энергии, накопленный в диэлектрике. Новые возможности электроразведки при поиске углеводородов изложены в [6].

Первая публикация по сейсмоэлектрическому методу, по-видимому, сделана А.Г. Ивановым в 1940 г. [7]. В последние годы появилось достаточно много работ по этому направлению и, в частности, по использованию сейсмоэлектрических явлений при поиске углеводородов [8-10].

В [10] опубликованы результаты лабораторных исследований по оценке фазового сдвига между электрическими и акустическими сигналами в зависимости от влагонасыщенности, нефте- и газоснабжения, пористости вмещающей среды.

В $[11,13]$ описаны результаты использования активного сейсмоэлектрического метода в морских условиях с одновременной подсветкой искусственными сейсмическими и электрическими источниками, на основании которых был сделан вывод о четырехкратном увеличении эффективного распознавания углеводородных месторождений.

\section{Алгоритм обработки шумовых сигналов}

В $[12,13]$ нами описан алгоритм извлечения потенциалов ВП из естественного электромагнитного поля Земли путем регистрации совокупного фазового сдвига шумовых сигналов в

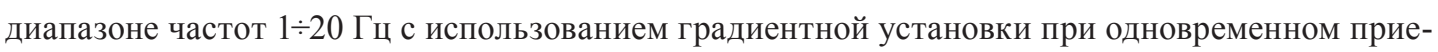
ме на две смежных электрических линии.

Был разработан двухканальный прибор ВПЕМПЗ-М1 («Шум-6»), результаты испытания которого на железорудном месторождении изложены в [14]. Ниже представлены данные апробирования этого прибора на углеводородной залежи на Ново-Михайловской площади Минусинского газового месторождения (рис. 1) в 2014 г. с использованием не только электрического шумового поля для метода ВП, но и в комбинации с сейсмическими шумами. В августе 2015 г. этот эксперимент был успешно повторен на двух площадях того же месторождения (Быстрянской и Ново-Михайловской).

В описываемом в статье приборе реализуются следующие алгоритмы и параметры выделения информации из шумовых сигналов.

Параметр ВП:

$$
\eta=\frac{\int_{0}^{T}\left[E_{x}(t)-\tilde{k} \cdot E_{y}(t)\right]^{2} d t}{\int_{0}^{T} E_{x}^{2}(t) d t},
$$


где $E_{x}(t)$ и $E_{y}(t)$ - соответственно ЭДС шумовых сигналов, наблюдаемых на двух смежных сложных электрических заземленных линиях (рис. $2 a$ ); $\widetilde{k}$ - коэффициент амплитудного выравнивания сигнала, устанавливаемого микроконтроллером прибора автоматически; [0, Т] - интервал наблюдения.

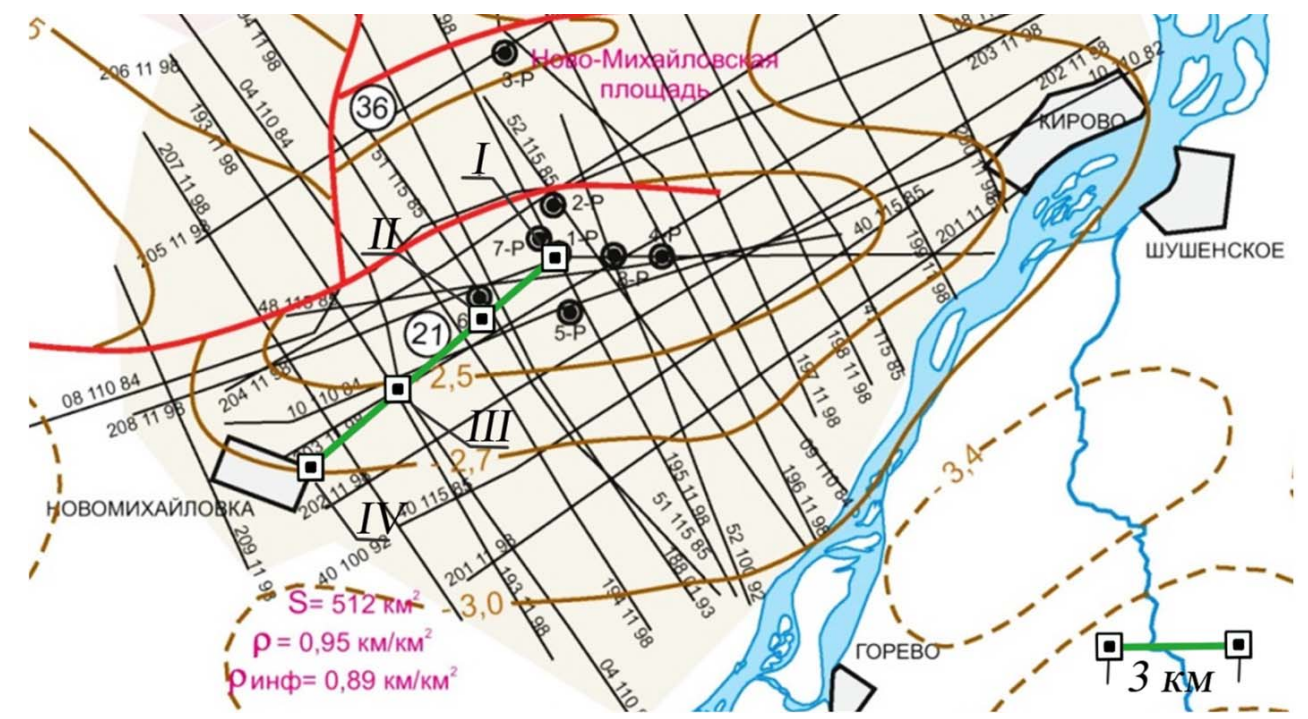

Рис. 1. Геологическая карта Ново-Михайловского газового месторождения. I, II, III, IV - точки наблюдения прибора ВПЕМПЗ 3-М1 («Шум-6»)

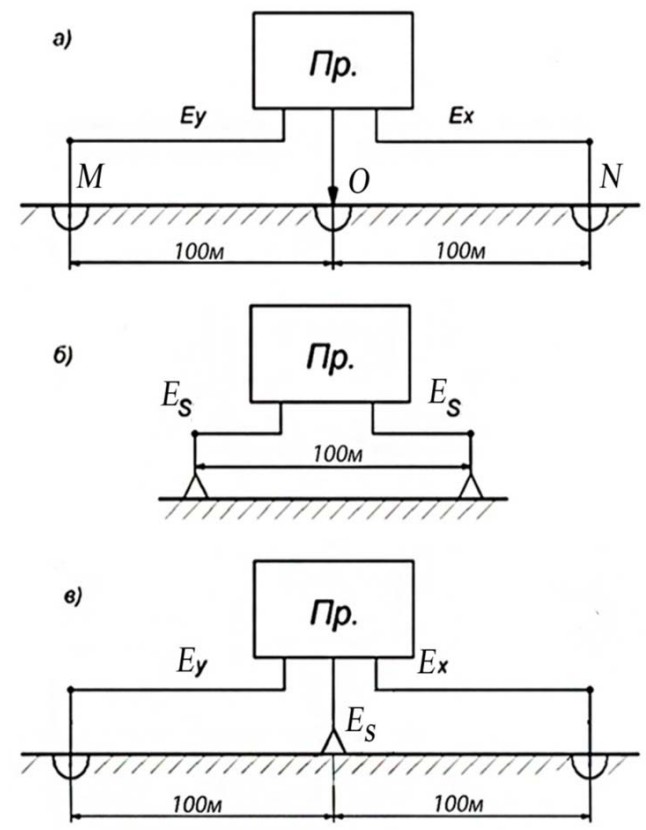

Рис. 2. Схема установки датчиков сигнала: а - для измерения параметра ВП ๆ; б - для регистрации ВКФ $R S S(\tau)$; в - для регистрации ВКФ $R E S(\tau)$ 
Как показано в [14], разряд потенциалов ВП соответствует пропусканию шумовых сигналов через фильтр нижних частот и появлению фазового сдвига по отношению к опорному сигналу, наблюдаемому в нормальном поле.

В случае малого фазового сдвига разность амплитуд сигналов соответствует этому сдвигу и параметр ВП определяет уровень разности потенциалов ВП.

В нормальном поле дисперсия разности $\left[E_{x}(t)-\widetilde{k} E_{y}(t)\right]^{2}$ должна стремиться к нулю. Знаменатель (1) означает операцию нормировки этой разности по дисперсии опорного шумового сигнала.

Прибор одновременно вычисляет функцию взаимной корреляции (ВКФ) сигналов $E_{x}(t) \otimes E_{y}(t)$, несущую информацию о постоянной времени разряда потенциалов ВП,

$$
R_{E E}(\tau)=\frac{\int_{0}^{T} E_{x}(t) \cdot E_{x}(t-\tau) d t}{\int_{0}^{T} E_{x}^{2}(t) d t},
$$

а также ВКФ - сейсмических шумов (рис. 2б).

$$
R_{S S}(\tau)=\frac{\int_{0}^{T} E_{S}(t) \cdot E_{S}(t-\tau) d t}{\int_{0}^{T} E_{S}^{2}(t) d t} .
$$

Параметр сейсмоэлектрического эффекта определяется через коэффициент взаимной корреляции электрического $E_{E}(t)$ и сейсмического $E_{S}(t)$ шумовых сигналов:

$$
R_{E S}(\tau)=\frac{\int_{0}^{T} E_{E}(t) \cdot E_{S}(t-\tau) d t}{\int_{0}^{T} E_{S}^{2}(t) d t} .
$$

В этом случае шумовые сигналы снимаются одновременно на одной точке наблюдения с приемной электрической линии $E_{E}(t)$ и с сейсмоприемника $E_{S}(t)$ (рис. 2в).

\section{Результаты полевых наблюдений}

На рис. 3 приведена структурная схема прибора «Шум-6», содержащего два предварительных усилителя, одинаковых по частотно-фазовым характеристикам, аналого-цифровой преобразователь и микроконтроллер, реализующие цифровым способом вышеприведенные алгоритмы.

В августе 2014 г. опытные работы проводились на Ново-Михайловской площади Минусинского газоконденсатного месторождения, в 70 км к югу от г. Абакана (Республика Хакасия). Газоконденсатная залежь находится на глубине 2200 м, общая площадь аномальной зоны $3 \times 3$ км². В 1990-1999 гг. месторождение было хорошо изучено разведочными скважинами, сейсморазведочным и электроразведочным методами. Наблюдение шумовых сигналов производилось в точках наблюдения I, II, III, IV по профилю $30^{\circ}$ на северо-восток от села Ново-Михайловское 


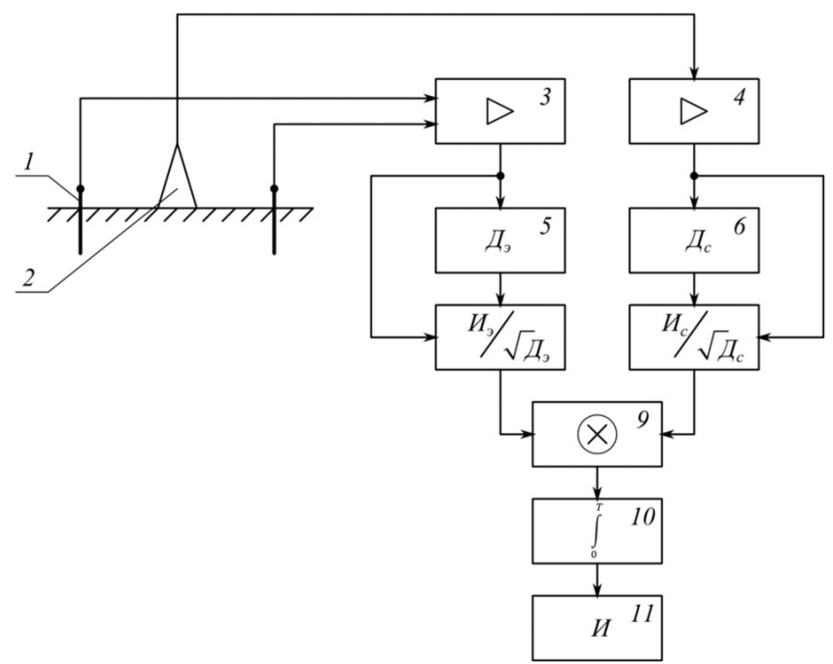

Рис. 3. Структурная схема прибора: 1 - датчик (диполь) электрического поля; 2 - сейсмоприемник; 3, 4 - усилители; 5, 6 - устройство вычисления дисперсий; 9 - перемножитель; 10 - интегратор; 11 индикатор

(рис. 1), где точка I находилась в центре аномалии около скважины «Факел», в 1990-х гг. давшей сильный фонтан газа.

Точка II находилась на расстоянии от центра аномалии в 3 км, III - в 6 км и IV - в 12 км. Время отсчета всех параметров Т было одинаковым и составляло 60 с. Длина электрических приемных линий $\mathrm{OM}=\mathrm{ON}$ равнялась 100 м. При наблюдении сейсмоэлектрического эффекта в центре линии MN длиной 200 м устанавливался сейсмоприемник. Для заземлений электрических линий использовали неполяризующиеся электроды.

На рис. 4 сведены основные результаты наблюдений коэффициентов $R_{E S}(0), R_{E E}(0), R_{S S}(0)$ и по точкам (пикетам) I, II, III, IV. Разброс показаний отсчетов измеряемых величин в течение дня при нулевом временном сдвиге $\tau$ отсчетов ВКФ доходил по отдельным пикетам от 10 до $30 \%$.

На рис. 4 точками отмечены среднеквадратичные значения. Средний уровень сигнала шумов на выходе датчиков находился в пределах 20 $\div 100$ мкВ.

Судя по графикам (рис. 4), ВКФ ES $\left(R_{E S}\right)$ спадает от точки I, расположенной в центре аномалии, вблизи скважины «Факел» от 0,99 до 0,2 - в точке IV на расстоянии 12 км от скважины. Это означает, что в аномальной зоне шумовые сейсмические сигналы совпадают по фазе с электрическими. По мере удаления в нормальную зону корреляции резко падают по причине существенного запаздывания сейсмического сигнала относительно электрического. На расстоянии 12 км при средней скорости 4000 м/с это запаздывание может составить $3 \mathrm{c}$, т.е. произойдет декорреляция рассматриваемых волн.

ВКФ ЕЕ $\left(R_{E S}\right)$, т.е. между сигналами с двух смежных электрических диполей, с расстоянием от аномалии ведет себя похожим образом с $R_{E S}$, максимум градиента поля мы наблюдаем в точке II на расстоянии 3 км от скважины, что может указывать на периферийный источник тока по отношению к центру аномалии, т. е растекание токов ВП с концов пластовой залежи газа. 

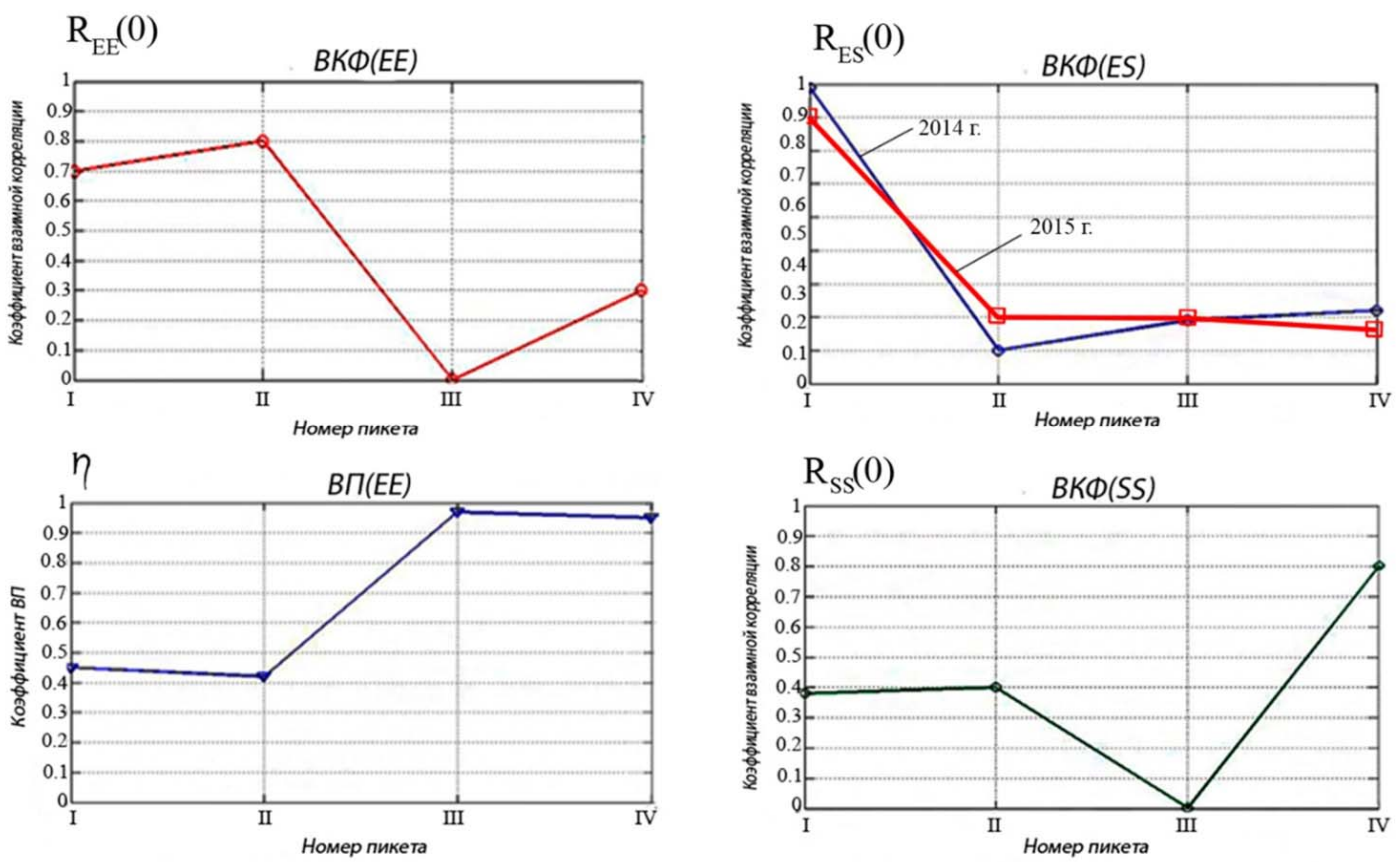

Рис. 4. Профильные характеристики коэффициентов взаимной корреляции и ВП

Этот процесс подтверждается наблюдением параметра ВП ๆ, нарастающим к периферии аномалии, в том числе и в точке IV по профилю северо-восточного направления.

ВКФ SS $\left(R_{S S}\right)$, получаемый из сигналов двух разнесенных сейсмоприемников, растет плавно от центра аномалии к периферии. Это может указывать на регистрации одинаковых, но смещенных по времени сигналов. При разносе сейсмоприемников на 200 м и скорости 4000 м/c, запаздывание по времени составит $t=0,05$ с. Так, для частоты $f=1$ Гц это соответствует запаздыванию по фазе $\Delta \varphi \approx 17^{\circ}$. В центре аномалии уменьшение коэффициента корреляции, повидимому, связано с влиянием продуктивного пласта.

Если эффект ES $\left(R_{E S}\right)$ вызван сейсмическим возмущением, то наблюдаемый коэффициент ВКФ SS в нормальной зоне не несет информации о сейсмоэлектрическом процессе и лишь характеризует интенсивность возмущающей сейсмической волны, поступающей с периферии.

На рис. 5 изображены ВКФ $R_{E S}(\tau)$ соответственно в аномальной (точка I) и нормальной зоне (точка IV) как функция временного сдвига $\tau$.

По уровню ВКФ $R_{E E}(\tau)$ (рис. 4) в центре аномалии (точка I) можно судить о том, что фазовых сдвигов нет и градиентная $\mathrm{EE}$ - установка по абсолютной величине $R_{E S}(0)$ - отмечает лишь дисперсию шума. Об этом же свидетельствует минимальный коэффициент ВП $\eta$ в точке I. Эффект ВП проявляется на периферии аномалиями в точках II, III, IV, что свидетельствует о растекании токов ВП через края аномалии, где проявляется градиент поля Е по направлению от точки I к точке IV.

ВКФ $R_{E S}(\tau)$ (рис. 5a), наоборот, над центром аномалии подчеркивает низкочастотные составляющие шумового сигнала, т.е. залежь газа действует как фильтр нижних частот. При этом над 

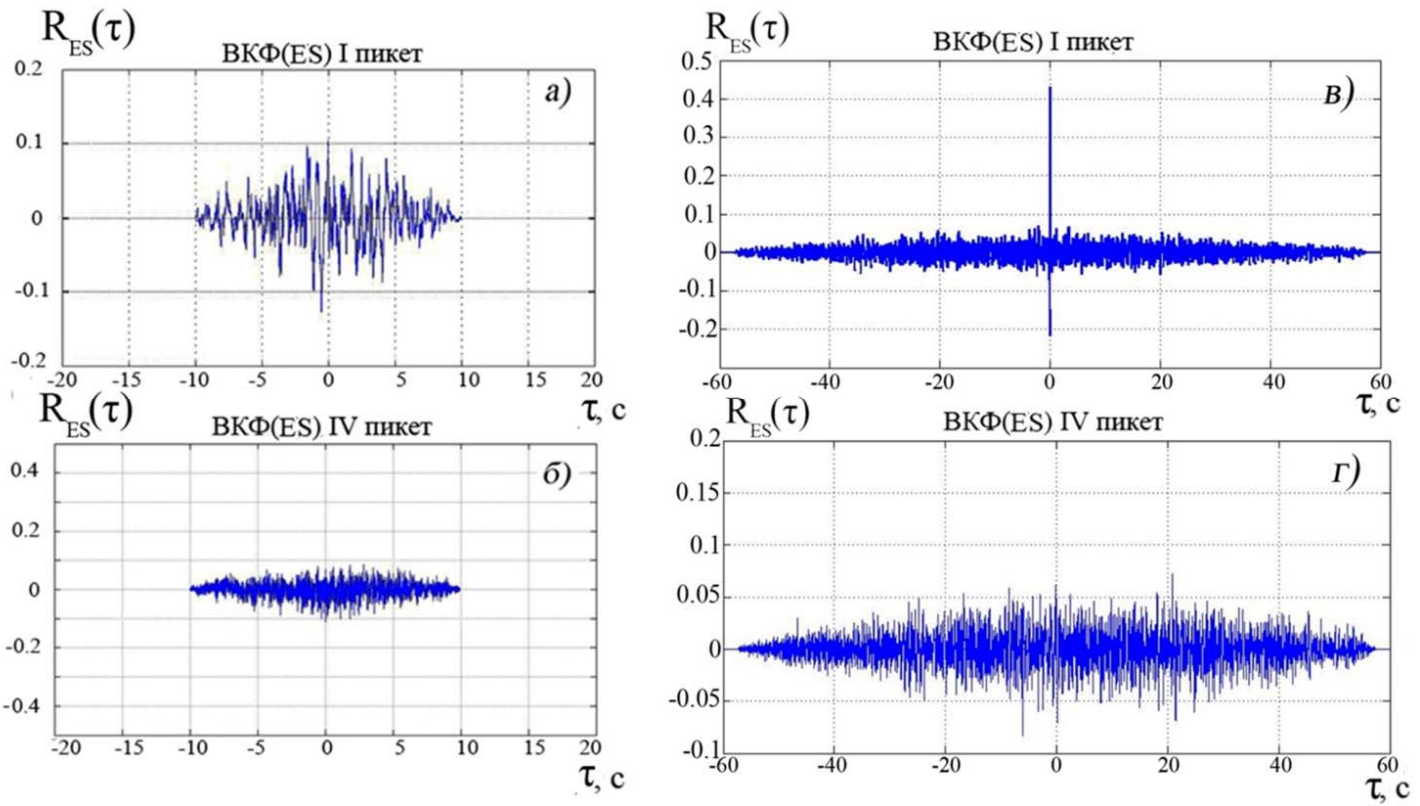

Рис. 5. Вид наблюдаемых функций ВКФ $R E S(\tau)$ на Ново-Михайловской площади: а - в аномальной (точка I); б - в нормальной зоне (точка IV), время усреднения 20 с; в - в аномальной (точка I); г - в нормальной зоне (точка IV), время усреднения $60 \mathrm{c}$

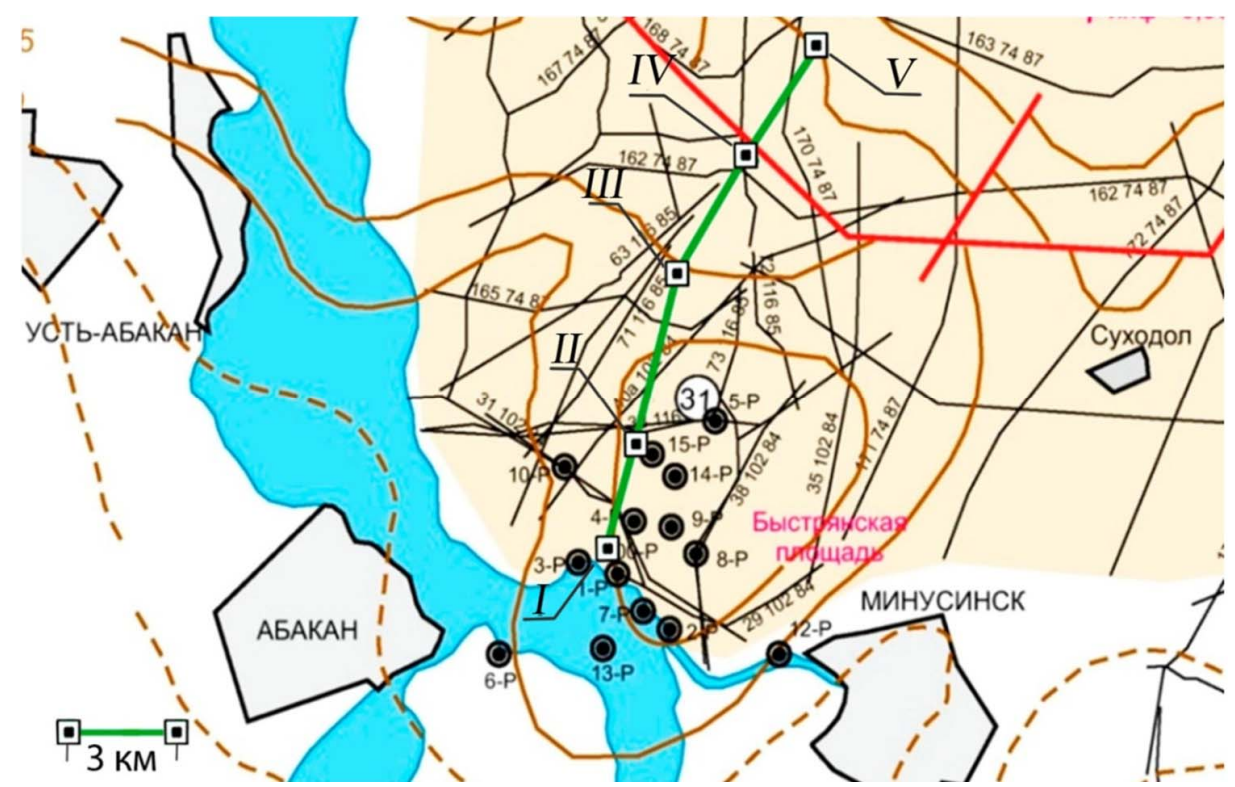

Рис. 6. Геологическая карта Быстрянской газовой площади

центром аномалии фазовый сдвиг электрического и сейсмического сигналов минимален и величина $R_{E S}(0)$ показывает совместную дисперсию шума. По мере удаления от аномалии временная форма $R_{E S}(\tau)$ приобретает обычную огибающую для полосового шума в диапазоне $1 \div 20$ Гц (рис. 5б). На рис. 6 приведена геологическая карта Быстрянской газовой площади с отметками точек 
наблюдения сейсмоэлектрического эффекта (I, II, III, IV, V), расположенных между собой на расстоянии 3 км. Глубина залегания продуктивной залежи на этой площади 1800 м.

На рис. 7, 8 показаны результаты наблюдения на Быстрянской площади (точка II - центр аномалии). Отношение сигнал/фон в точке II существенно возросло при использовании трех сейсмоприемников. На рис. 9 приведена ВКФ в нормальной зоне (точки IV, V).

Предварительно можно сделать заключение, что параметры $R_{E E}(0), R_{E E}(\tau), \eta ; R_{E S}(0), R_{E S}(\tau)$ несут новые, по сравнению с обычной сейсморазведкой, информационные атрибуты. Требуется не только расширить объем наблюдений на различных месторождениях нефти и газа, но и разработать соответствующие теоретические модели.

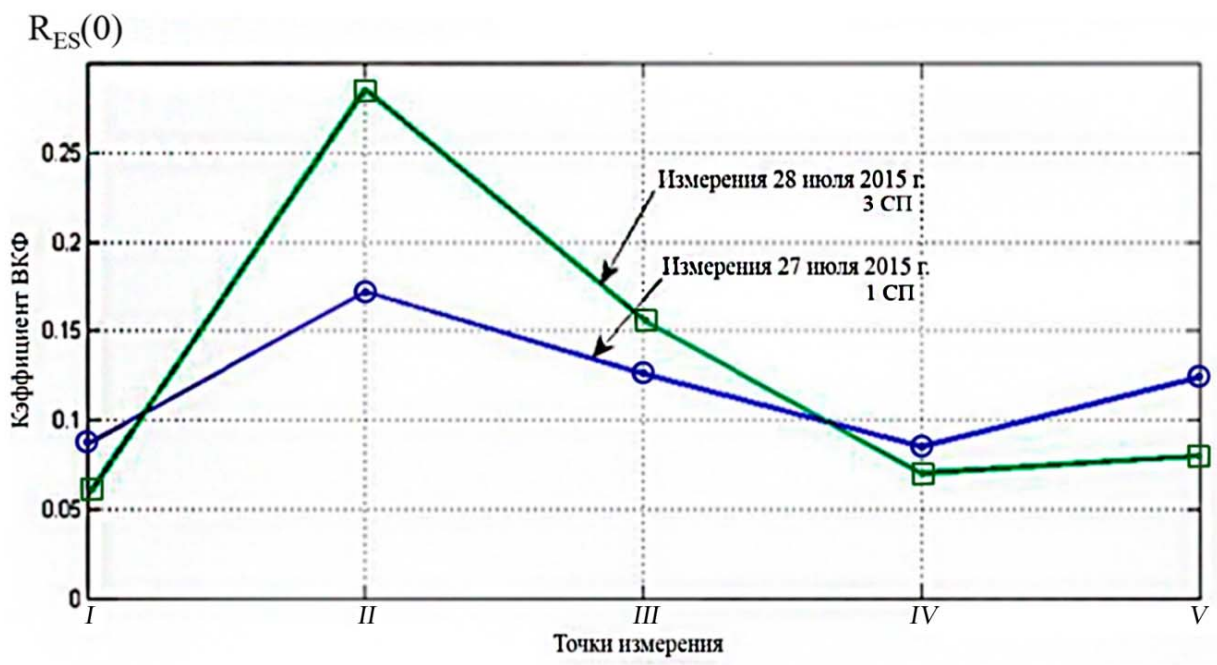

Рис. 7. Профильные характеристики коэффициентов взаимной корреляции на Быстрянской площади

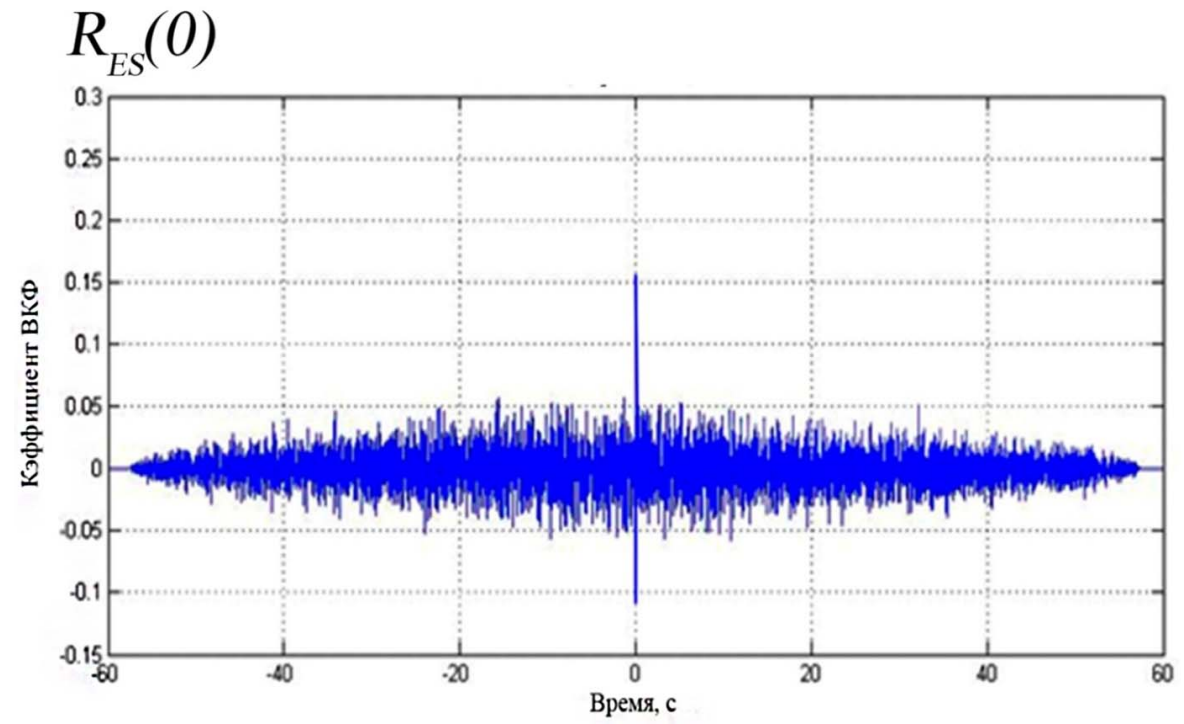

Рис. 8. Взаимно-корреляционная функция в центре Быстрянской газовой площади 


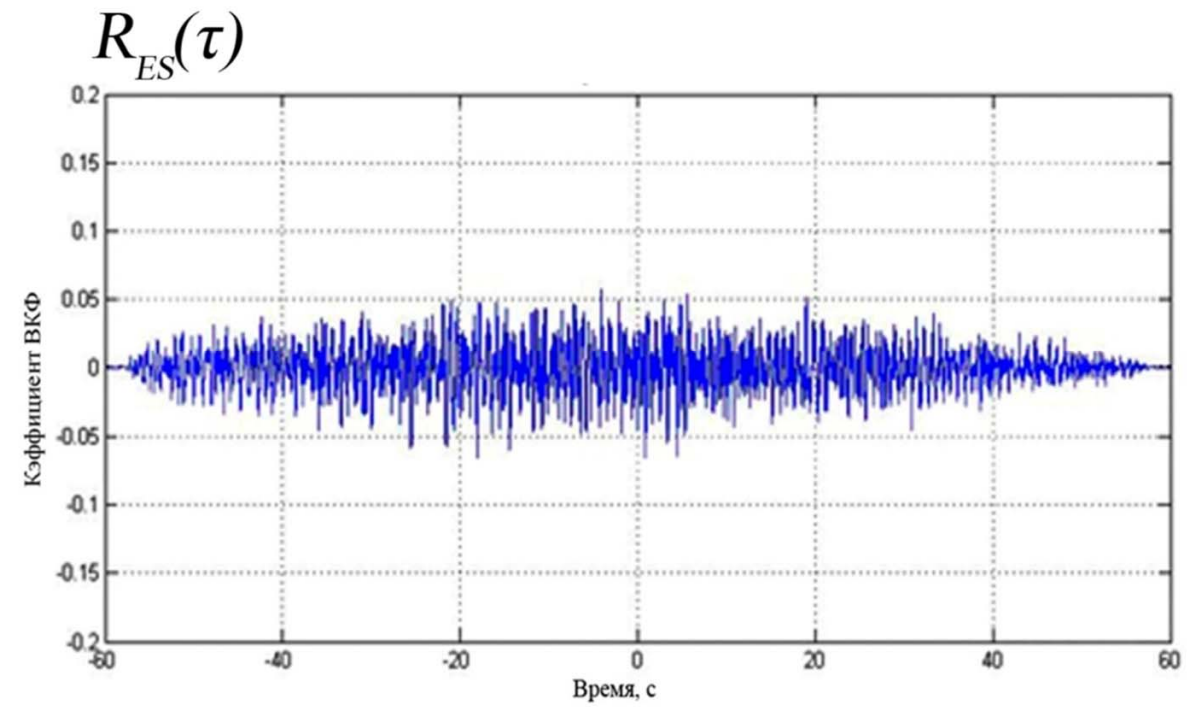

Рис. 9. ВКФ на периферии Быстрянской газовой площади

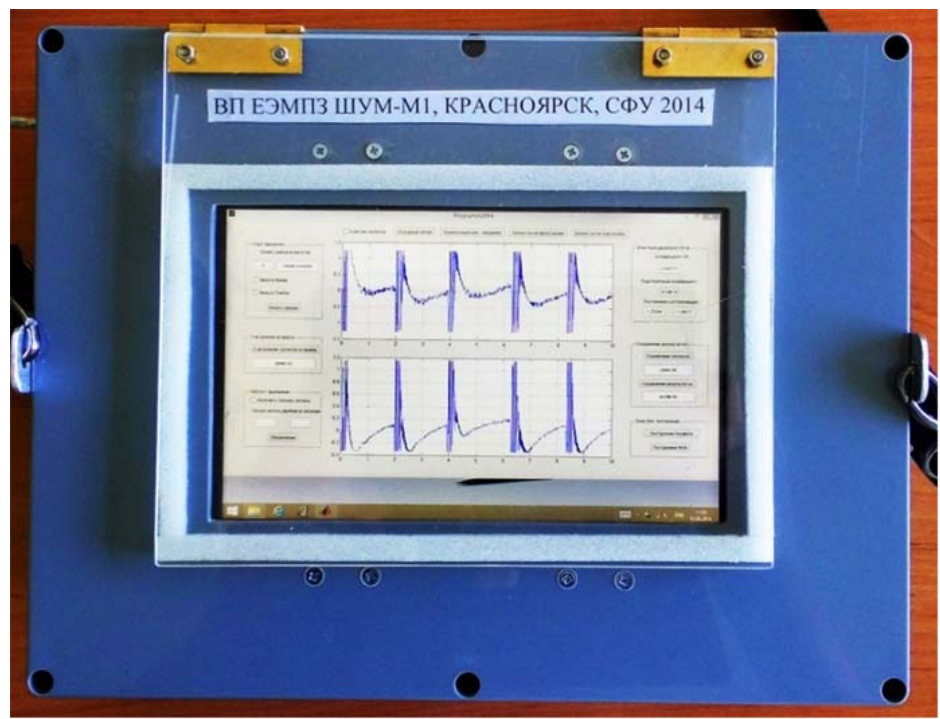

Ри. 10. Внешний вид прибора ВПЕМПЗ 3-М1

Гипотетическая модель физических явлений, обусловливающих наблюдаемые результаты, нам видится такой: пластовая залежь углеводородов может быть представлена плоским конденсатором, наполненным мягкой пористой породой, включающей флюиды углеводородов с повышенной диэлектрической проницаемостью $\varepsilon$.

Окружающая горная порода представляет ионопроводящую среду с существенно более высокой проводимостью. Под действием постоянного электростатического поля Земли, напряженность которого на поверхности Земли составляет величину $\mathrm{E}_{z} \approx 120$ B/M, заряжается природный конденсатор, образуемый залежью углеводорода. 
Внешнее возмущение электрическими флуктуациями теллурического поля либо сейсмическими шумовыми волнами приводит к процессу стекания зарядов с торцовых поверхностей залежи, электрическое поле которых наблюдается на поверхности Земли.

Важным преимуществом нового метода является его «пассивность», т.е. отпадает необходимость использовать специальные источники возбуждения электрического либо сейсмического поля.

Ввиду несложности проведения работ с одним переносным прибором (рис. 10) массой до 3 кг описанный метод может быть использован на стадии доразведки обнаруженных сейсморазведкой аномалий.

Просматривается вариант постановки работы сейсмоэлектрическим методом путем развертывания вдоль профиля сейсмических кос и дополнительных датчиков сигналов электрического поля. В этом случае сейсмостанция может производить обработку описанными в статье алгоритмами одновременно с проведением сейсморазведочных работ как пассивным, так и полуактивным методом с использованием сейсмических излучателей.

\section{Заключение}

1. На основе взаимно-корреляционной обработки шумовых сигналов естественного электромагнитного и сейсмического полей Земли на двух площадях Минусинского газоконденсатного месторождения: Быстрянской (глубина 1800 м) и Ново-Михайловской (глубина 2200 м), был отмечен аномальный эффект, превышающий в 5-7 раз нормальный фон.

2. На Ново-Михайловской площади это месторождение было отмечено также эффектом вызванной поляризации на основе фазовой и корреляционной обработки шумовых сигналов ЕЭМПЗ в диапазоне частот 1 20 Гц. На Быстрянской площади метод ВПЕМПЗ из-за недостатка времени не применялся.

3. Гипотетически зарегистрированные эффекты можно объяснить одним и тем же явлением - накоплением электрического заряда в залежи за счет электрического поля Земли и появлением токов разряда на окружающую горную породу под действием флуктуаций теллурического поля (вызванная поляризация) и шумовых возмущений сейсмическими полями естественного происхождения (землетрясение и пр.).

4. Разработан переносной двухканальный прибор ВП ЕЭМПЗ-М1, позволяющий работать обоими методами. При этом ВПЕМПЗ дал положительные результаты также при работе на рудном месторождении [14].

Проект поддержан за счет средств, предоставленных РФФИ, Правительством Красноярского края, Краевым фондом науки.

\section{Список литературы}

[1] Артюнов С. П., Давыдов В. Ф., Кузнецов О. Л. Явление генерации инфразвуковых волн нефтегазовой залежью. Научное открытие № 109, 1999. [Artunov S. P., Davidov V. F., Kuznetsov O. L. The phenomenon of generation of infrasound waves of oil and gas deposits. Scientific discovery. 1999, 109 (in Russian)] 
[2] Ведерников Г. В. Изучение микросейсм при сейсморазведочных работах МОГТ для прогнозирования залежей углеводородов. Тезисы доклада МПК, 24-26 ноября 2008г. СНИИГГИМС, Новосибирск 2009, 48-53. [Vedernikov G. V. The study microseism when CDP seismic survey to predict hydrocarbon deposits. Theses of the report MPC, 24-26 November 2008. SNIIGGIMS, Novosibirsk, 2009, 48-53 (in Russian)]

[3] Ведерников Г. В. Прогноз залежей углеводородов по характеристикам микросейсм. Новосибирск: изд. Свинин и сыновья, 2012, 194 с. [Vedernikov G. V. The forecast of hydrocarbon deposits on the characteristics microseism. Featured Articles, Ed. Svinin and sons, Novosibirsk, 2012, 194 p. (in Russian)]

[4] Бердичевский М. И. Электрическая разведка методом теллурических токов. Гос. н-т изд. нефтяной и горно-топливной литературы, М., 1960, 231 с. [Berdichevskiy M. I. Electric prospecting method of telluric currents. State scientific and technical publishing house of the oil and mining and fuel literature, Moscow, 1960, 231 p. (in Russian)]

[5] Кормильцев В. В. Переходные процессы при вызванной поляризации. М.: Наука, 1980, 112 c. [Kormilcev V. V. Transients at induced polarization. Moscow, Science, 1980, 112 p. (in Russian)]

[6] Тригубович Г. М., Эпов М. И. Новые возможности электромагнитной разведки. Тезисы доклада научно-практической конференции 24-26 ноября 2008 г., СНИИ ГИМС, Новосибирск, 2009, 16-19. [Trigubovich G. M., Epov M. I. New features electromagnetic surveying. Abstracts of scientific-practical conference report 24-26 November 2008. SNIIGGIMS, Novosibirsk, 2009, 16-19. (in Russian)]

[7] Иванов А. Г. Сейсмоэлектрический эффект второго рода. Изв. АН СССР, серия географическая и геофизическая, 1940, 5, 18-21. [Ivanov A. G. Seismic and electrical effect of the second kind. Proceedings of the Academy of Sciences of the USSR, a series of geographical and geophysical, 1940, 5, 18-21 (in Russian)]

[8] Потапов О. А., Лизун С. А., Кондрат В. Ф. Основы сейсмоэлектроразведки. М.: Недра, 1995, 268 c. [Potapov O. A., Lizun S. A., Kondrat V. F. Basics of seismic and electrical prospecting. Moscow, Nedra, 1995, 268 p. (in Russian)]

[9] Агеева О. А., Светов Б. С., Шерман Г. Х. Сейсмоэлектрический эффект второго рода в горных породах. Геология и геофизика. 40, 8, 51-57. [Ageeva O. A., Svetov B. S., Sherman G. H. Seismic and electrical effect of the second kind in the rocks. Geology and geophysics. 40, 8, 51-57 (in Russian)]

[10]Агеева О. А. Использование сейсмоэлектрических преобразований в породах для прогнозирования характера насыщения порового пространства. Геофизика. 2008, 1, 16-21 [Ageeva O. A. The use of seismic-electrical conversions in the rocks to predict the nature of the pore space saturation. Geophysics. 2008, 1, 16-21 (in Russian)]

[11] Мельников В. П., Лисов В. И., Брюховецкий О. С., Бобровников Л. З. Инновационная геофизика: бинарные технологии прямых поисков месторождений полезных ископаемых. Ч. 2. Инженер-нефтяник. М.: 000 «Ай Ди Эс Дриллинг», 2011, 2. [Melnikov V. P., Lisov V. I., Brukhovetsky O. S., Bobrovnikov L. S. Innovative geophysics: binary technology direct exploration of mineral deposits. Part 2. Petroleum engineer. Moscow, IDS Drilling, 2011, 2 (in Russian)] 
[12]Мельников В. П., Лисов В. И., Брюховецкий О. С., Бобровников Л. З. Инновационная геофизика: бинарные технологии прямых поисков месторождений полезных ископаемых. Ч. 1. // Инженер-нефтяник. М.: 000 «Ай Ди Эс Дриллинг», 2011, 1, 47-51. [Melnikov V. P., Lisov V. I., Brukhovetsky O. S., Bobrovnikov L. S. Innovative geophysics: binary technology direct exploration of mineral deposits. Part 1. Petroleum engineer. Moscow, IDS Drilling, 2011, 1 (in Russian)]

[13]Шайдуров Г. Я., Козлов Ю. Н., Маркушин Я. В. Дифференциальный метод извлечения информации о потенциалах ВП из естественного электромагнитного поля Земли. Геофизическая аппаратура. Ленинград: Недра, 1991, 97, 35-42. [Shaidurov G. Ya., Kozlov U. N., Markushin Ya. V. The differential method of extracting information about the potentials induced polarization of the natural electromagnetic field of the Earth. Geophysical equipment. Leningrad, Nedra, 1991, 97, 35-42 (in Russian)]

[14] Шайдуров Г. Я., Потылицын В. С. Некоторые результаты полевых испытаний метода вызванной поляризации на основе выделения информации из естественного электромагнитного поля Земли. Приборы и системы разведочной геофизики. ИнформГеофизСервис, 2012, 4, 51-54. [Shaidurov G. Ya., Potylitsyn V. S. Some results of the field test of the method of induced polarization on the basis of information extraction from natural electromagnetic field of the Earth. Devices and systems of exploration geophysics. Inform GeoPhisService, 2012, 4, $51-54$ (in Russian)] 